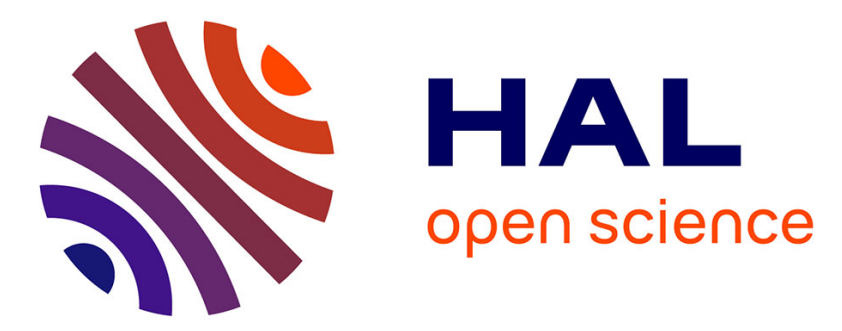

\title{
WAVESPEEDS MEASUREMENTS IN ANISOTROPIC MATERIALS BY USING LASER GENERATED ULTRASOUND
}

Bernard Castagnede

\section{- To cite this version:}

Bernard Castagnede. WAVESPEEDS MEASUREMENTS IN ANISOTROPIC MATERIALS BY USING LASER GENERATED ULTRASOUND. Journal de Physique IV Proceedings, 1992, 02 (C1), pp.C1-793-C1-796. 10.1051/jp4:19921173 . jpa-00251134

HAL Id: jpa-00251134

https://hal.science/jpa-00251134

Submitted on 1 Jan 1992

HAL is a multi-disciplinary open access archive for the deposit and dissemination of scientific research documents, whether they are published or not. The documents may come from teaching and research institutions in France or abroad, or from public or private research centers.
L'archive ouverte pluridisciplinaire HAL, est destinée au dépôt et à la diffusion de documents scientifiques de niveau recherche, publiés ou non, émanant des établissements d'enseignement et de recherche français ou étrangers, des laboratoires publics ou privés. 


\title{
WAVESPEEDS MEASUREMENTS IN ANISOTROPIC MATERIALS BY USING LASER GENERATED ULTRASOUND
}

\author{
B. CASTAGNEDE
}

Laboratoire de Mécanique Physique, URA CNRS 867, Université de Bordeaux I, 351 Cours de la Libération, F-33405 Talence cedex, France

\begin{abstract}
Wavespeed measurements made on the quasi-longitudinal ( $\mathrm{qL}$ ) mode have been achieved in two composite materials (i.e. a 1-D glass/epoxy and a 2-D SiC/SiC) by using a correlation algorithm between the measurement signal at a given observation angle, and a reference signal recorded at normal incidence. The wavespeed measurement at normal incidence is obtained, when possible, by correlating the direct $\mathrm{qL}$ ray with the $3 \mathrm{qL}$ multiple reflection. The $\mathrm{qL}$ wavespeeds measured by the laser method are then compared to the phase velocities acquired by standard ultrasonics techniques. The agreement is quite acceptable in most cases. When dealing with laser generated ultrasound, the wavefront of any given ray is propagated at the group velocity. The correlation measurements, should provide wavespeeds which tend to be close to such ray surface velocity. However, the difference between the two wavespeeds is small on the qL mode (generally less than $10 \%$ ) and can be as a first approximation safely ignored.
\end{abstract}

\section{INTRODUCTION}

The generation of ultrasonic waves by laser impacting a solid, is nowadays a well established procedure with numerous applications in QNDE [1]. A definite advantadge of such a mechanism is to launch at the same time Lamb waves [2], surface waves [3] and bulk waves. On the other hand, a significant drawback relates to the presence of head waves [4,5] arriving, beyond the critical angles, just before the transverse waves. When considering bulk modes, one has to distinguish between the thermoelastic regime, where the source is represented by a dipole in the surface plane, and for larger output power of the laser, the ablation regime with a monopolar source orthogonal to the surface. When the laser is operated in the first regime, there is no damage experienced by the sample, and only transverse waves are ideally obtained. Conversely, in the ablation regime, the sample is damaged, and longitudinal waves are mainly produced. The exact threshold between both regimes is generally very sharp and depends on the thermal properties, i.e. the coefficient of linear expansion, the coefficient of heat conduction, and the specific heat. 
The bulk modes produced by laser impacting a solid are transient divergent waves, which are analogous to the seismic waves launched by an earthquake. For that reason theoretical models describing the propagation of laser generated ultrasound have been borrowed to earthquake engineering [6] and share with it some of the basic concepts (e.g. the dipolar moment tensor), and standard techniques to predict the theoretical displacement fields such as the Cagniard-De Hoop inversion method [7]. These, in turns, have been calculated for isotropic solids [8,9], but the generalization to include anisotropy in the computational treatment is a formidable problem not yet completely solved [10].

Despite these limitations, in terms of rigorous predictions of the acoustical fields radiated by transient elastic waves in anisotropic solids, experimenters have been prone to perform some wavespeeds measurements, and subsequent elastic constants calculations, in single crystals as well as with composite materials [11,12]. The simpliest approach consists in doing these measurements at normal incidence, but unfortunately necessitates several sample orientations in order to retrieve the complete set of elastic constants [11]. This last point is a serious restriction to characterize composite materials solely available in thin sheets. In such a case, one needs to design scanning experiments enabling to detect elastic waves along various directions in the sample [12]. By doing so, further difficulties arise from the fact that one has to take into account group instead of phase velocities [13] (the two velocities are degenerated along principal directions). This has been discussed recently, as well as with the implications of phonons focusing effects, for the propagation of transient waves in silicon single crystals [14], but these results apply equally well for other anisotropic materials .

\section{EXPERIMENTAL RESULTS AND DISCUSSION}

Due to the intricacies in measuring both transverse waves as discussed in [12], one limits ourself here to the precise determination of velocities of the qL mode by using a cross-correlation technique. Measurements were performed on two different composite materials, i.e. i) a 1-D glass/epoxy $5.25 \mathrm{~mm}$ and ii) a 2-D SiC/SiC $3.35 \mathrm{~mm}$ thick plates. A characteristic epicenter waveform obtained, with a $1.3 \mathrm{~mm}$ aperture piezoelectric transducer, when the available pulsed Nd-YAG (10 ns) laser system is used in the intermediate regime, is shown on Figure 1 for the glass/epoxy sample. The absolute timing of the experiment is done by triggering a fast photodiode resulting in the sharp rise peak at the beginning of the recording. Coming afterwards are the longitudinal wave (labeled $L$ on the graph) as well as its first multiple reflection 3L. The expected time arrivals of the two transverse waves are depicted with arrows by $\mathrm{T} 1$ and $\mathrm{T} 2$. These arrivals were obtained by using prior knowledge of the phase velocities which were determined by using for that purpose the LMP (Laboratoire de Mécanique Physique) ultrasonic spectrointerferometer. It is worthwhile to note that the shape of subsequent off-epicenter $\left(\theta \neq 0^{\circ}\right) \mathrm{qL}$ mode remains unchanged up to very large observation angles (in the range of $\theta=70$ to $80^{\circ}$ ), meaning in turns that the correlation measurement technique is meaningful for broad angular regions. This is somewhat an advantadge of the laser impacting method when compared to immersion techniques where there exist a limit angle on the $\mathrm{qL}$ mode (e.g. approximately $45^{\circ}$ for the 1-D glass/epoxy composite).

The experimental results in terms of the wavespeed measurements on the $q \mathrm{~L}$ mode obtained by using the laser impacting method are shown on Figure 2 and 3 for the 1-D glass/epoxy and the 2-D SiC/SiC composite materials respectively. On Figure 2, the experimental data, collected at the same time for the isotropic plane $(x)$ as well as for the anisotropic plane $(+)$, agree quite satisfactorily with those acquired on 


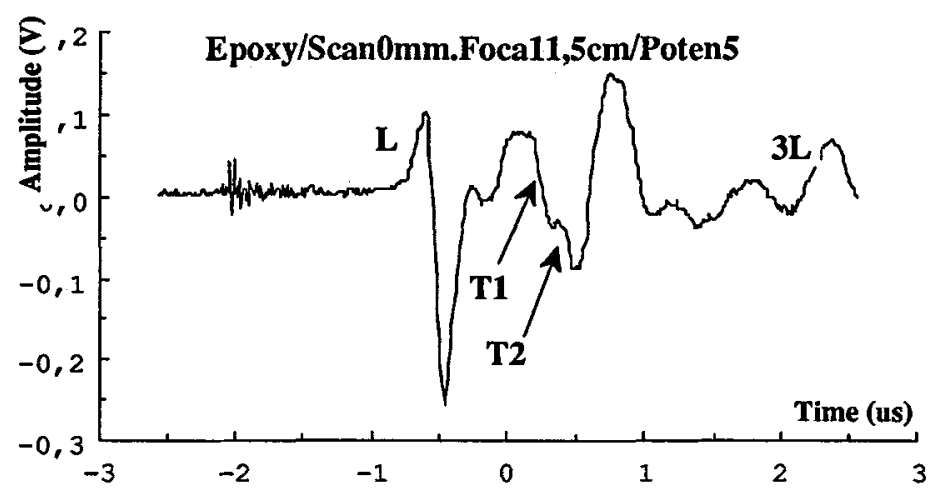

Figure 1: Temporal waveform at normal incidence in a 1-D glass/epoxy composite material.

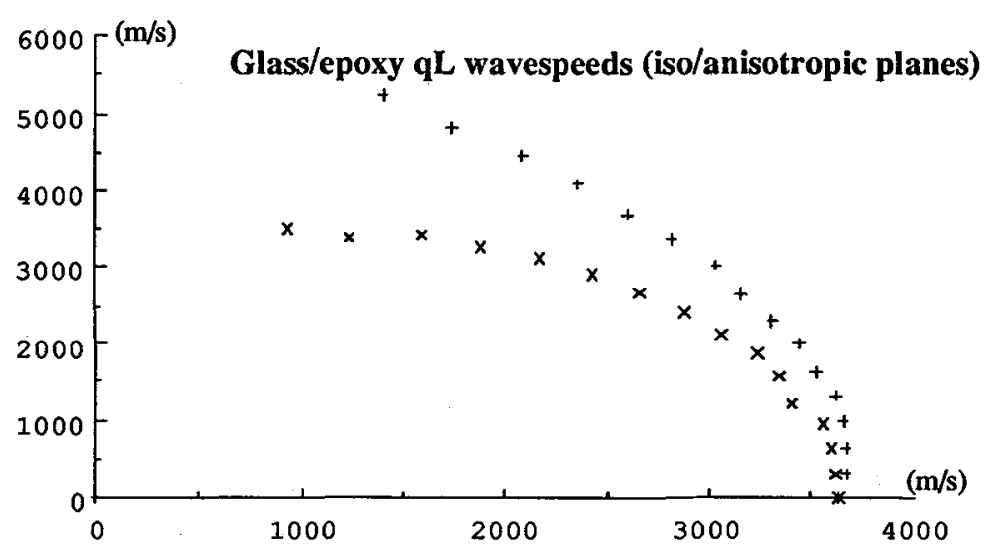

Figure 2: Polar plot of the qL wavespeeds in the isotropic $(x)$ and anisotropic $(+)$ planes of the 1-D glass/epoxy composite material.

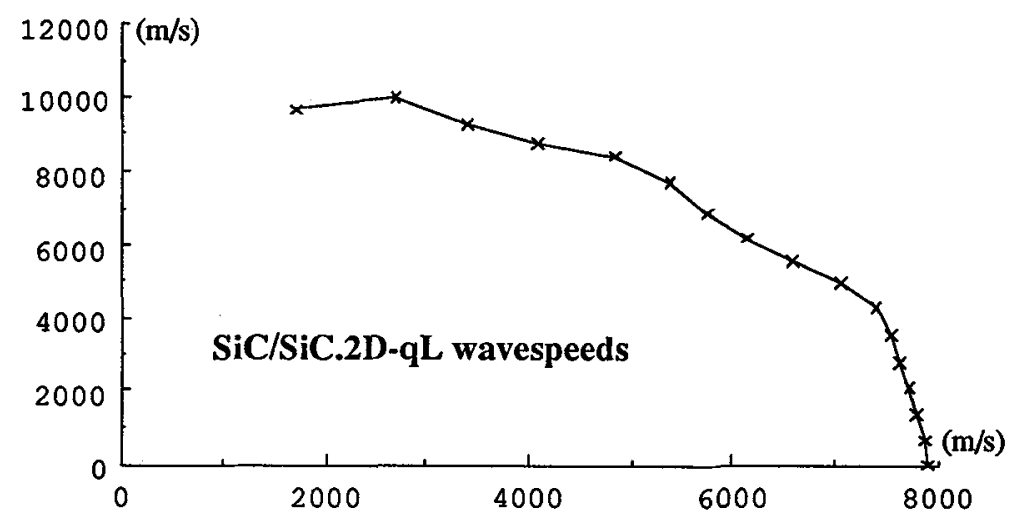

Figure 3: Polar plot of the $\mathrm{qL}$ wavespeeds in a 2-D SiC/SiC composite material. 
the LMP ultrasonic spectro-interferometer. Furthermore, the standard hypothesis of a 1-D composite material being isotropic in the plane which is orthogonal to the fibers is correctly verified with respect to the propagation of the $\mathrm{qL}$ acoustical wave. The results obtained with the 2-D SiC/SiC composite are more problematic as one can observe a waving pattern of the wavespeeds versus angle. As a matter of fact, this trend is related to the large spatial periodicity of the fiber network, i.e. the distance of two consecutive fibers which is in the range of $1 \mathrm{~mm}$. In order to retain some precision with the wavespeed measurements for such a very thin plate (only $3.35 \mathrm{~mm}$ in thickness), one needs to focus the incident laser beam down to an optical spot in the range 0.5 to $1 \mathrm{~mm}$. This implies that the surface of the material during the scanning procedure is probed in different locations, i.e. onto the fibers or somehow between two adjacent fibers. In such a case, it is obvious that the results will show up some discontinuities which are related to the peculiar zones of the material under investigation. Consequently, it seems difficult with the impacting laser technique to characterize the overall properties of thin sheet heterogeneous composite materials, where thickness is only a few times the spacing between consecutive fibers.

\section{LITERATURE CITED}

[1] HUTCHINS, D.A., Ultrasonic generation by pulsed lasers, in Physical Acoustics, Vol. XVIII, W.P. MASON \& R.N. THURSTON, Edts., Academic Press, New York (1988), pp. 21-123.

[2] JAROSZ, B.J., Ultrasonic surface modes generated by laser pulses on duraluminium, Ultrasonics 29, 53-57 (1991).

[3] NAKANO, H. and NAGAI, S., Laser generation of antisymmetric Lamb waves in thin plates, Ultrasonics, 29, 230-234 (1991).

[4] AKI, K. and RICHARDS, P.G., Quantitative Seismology, Freeman, San Francisco, vol. 1, (1980), pp. 383-477.

[5] MUSGRAVE, M.J.P. and PAYTON, R.G., Head wave contributions to elastic wave fields in a transversely isotropic half-space, Quart. J. Mech. Appl. Math. 34, 235-250 (1981).

[6] MUSGRAVE, M.J.P. and PAYTON, R.G. , On the head wave envelope in a half-space of arbitrary elastic anisotropy, Quart. J. Mech. Appl. Math. 35, 173-181 (1982).

[7] MIKLOWITZ, J., The theory of elastic waves and waveguides, North-Holland, Amsterdam (1978).

[8] ROSE, L.R.F., Point-source representation for laser-generated ultrasound, J. Acoust. Soc. Am. 75, 723-732 (1984).

[9] SCHLEICHERT, U., Die Theorie der optischen Erzeugung elastischer Wellen in Festkörpern, Ph.D Thesis, University of Kassel (1989).

[10] VAN DER HIJDEN, J.H.M.T., Propagation of transient elastic waves in stratified anisotropic media, North-Holland, Appl. Math. \& Mech., Vol. 32 (1987).

[11] AUSSEL, J.-D. and MONCHALIN, J.-P., Precision laser-ultrasonic velocity measurement and elastic constant determination, Ultrasonics, 27, 165-177, (1989).

[12] CASTAGNEDE, B., KIM, K.Y., SACHSE, W. and THOMPSON, M.O., Determination of the elastic constants of anisotropic materials using laser-generated ultrasonic signals, J. Appl. Phys. 70, 150-157 (1991).

[13] EVERY, A.G. and SACHSE, W., Determination of the elastic constants of anisotropic solids from acoustic wave group velocity measurements, Phys. Rev. B 42, 8196-8205 (1990).

[14] EVERY, A.G., SACHSE, W., KIM, K.Y. and THOMPSON, M.O., Phonon focusing in silicon at ultrasonic frequencies, Phys. Rev. Lett. 65, 1446-1449 (1990). 